\title{
A novel self-assembled nano micelle as a highly efficient artificial peroxidase based on hexadecyl trimethyl ammonium bromide and cytochrome $\mathrm{c}^{1}$
}

Tian Yang ${ }^{\mathrm{a}}$, Yu-Shuai Zhang ${ }^{\mathrm{a}}$, Xiao-Lu Yang ${ }^{\mathrm{a}}$, Fang-Yong Geng ${ }^{\mathrm{a}}$, Bao-Lin Xiao ${ }^{\mathrm{a}}$, MengMeng $\mathrm{Xu}^{\mathrm{a}}$, Di Li ${ }^{\mathrm{a}}$, Jun Hong ${ }^{\mathrm{a}, \mathrm{b},{ }^{*}}$ and Ali Akbar Moosavi-Movahedi ${ }^{\mathrm{c}}$

${ }^{a}$ School of Life Sciences, Henan University, Kaifeng 475000, China

${ }^{\mathrm{b}}$ Institute of Biotechnology, Henan University, Kaifeng 475000, China

${ }^{\mathrm{c}}$ Institute of Biochemistry and Biophysics, University of Tehran, Tehran, Iran

\begin{abstract}
A novel artificial peroxidase (AP) with highly catalytic efficiency was designed using hexadecyl trimethyl ammonium bromide $(\mathrm{CTAB}, 3 \mathrm{mM})$ nano-micelles and bovine heart cytochrome c $($ Cyt $c, 0.5 \mu \mathrm{M})$ in $100 \mathrm{mM}, \mathrm{pH} 8.0$ phosphate buffer at $25^{\circ} \mathrm{C}$. The catalytic rate $\left(\mathrm{k}_{\text {cat }}\right)$ and Michaelis-Menten $\left(\mathrm{K}_{\mathrm{m}}\right)$ of the AP were determined to be $0.311 \pm 0.013$ $\mathrm{s}^{-1}$ and $8.64 \pm 0.6 \mu \mathrm{M}$. The catalytic efficiency was $0.0360 \pm 0.0020 \mu \mathrm{M}^{-1} \mathrm{~s}^{-1}$ (about $50 \%$ the efficiency of native horseradish peroxidase). The Ultraviolet-visible spectrophotometer and Circular Dichroism techniques were applied to study the properties of the CTAB-Cyt c nano-micelle. Designed AP can be applied instead of native horseradish peroxidase.
\end{abstract}

Keywords: Catalytic efficiency, artificial peroxidase, nano-micelle, cytochrome c, CTAB

\section{Introduction}

Recently, designs of heme-containing proteins are becoming research hotspots, in order to interpret the relationships between the function and structure of the proteins during their catalytic processes. Artificial peroxidases could be assembled not only for different applications, but to reveal the catalytic mechanisms [1-4].

Sodium dodecyl sulfate (SDS) is an amphipathic anion surfactant. It is being used widely in protein refolding [5-8], enzyme activation [9], stabilizing of the secondary structure of some proteins [10-11] and modeling membrane or other hydrophobic environments [10-12] at above critical micelle concentration $(\mathrm{CMC})$. Cytochrome $\mathrm{c}(\mathrm{Cyt} c)$ is a heme-containing protein, which has a $3 \mathrm{~nm}$ diameter [13], 104 amino acids and very low peroxidase activity [13-15]. In a previous study, a nano-artificial

\footnotetext{
${ }^{1}$ Tian Yang, Yu-Shuai Zhang and Xiao-Lu Yang contributed equally to this work.

* Address for correspondence: Jun Hong, School of Life Sciences, Henan University, Kaifeng 475000, China. Tel.: +86 13781161597; Fax: +86 371 23886258; E-mail: hongjun@henu.edu.cn.
} 
peroxidase was constructed by self-assembly with SDS and Cyt $c$ in $50 \mathrm{mM}$, pH 10.5 sodium phosphate buffer. The catalytic efficiency of this AP can reach $30 \%$ of native horseradish peroxidase [16], however, it is worth considering how to reduce the optimum $\mathrm{pH}$ and increase the catalytic efficiency of the artificial peroxidiase for further various practical applications.

In this report, hexadecyl trimethyl ammonium bromide (CTAB), an amphipathic canion surfactant, was used to mix with Cyt $c$ by self-assembly to design a novel nano structured artificial peroxidase with lower optimum $\mathrm{pH}$ and higher catalytic activity.

\section{Experimental}

\subsection{Reagents}

Horseradish peroxidase (HRP), guaiacol, CTAB and bovine heart Cyt $c$ were purchased from Sigma. Other chemicals were of analytical grade and used without further purification. Double distilled water was used throughout these studies.

\subsection{Preparation of CTAB-Cyt c nano-micelle $(A P)$ and the kinetic measurements}

Artificial peroxidases (AP) could be constructed by self-assembly through addition of Cyt $c$ into 100 $\mathrm{mM}$ phosphate buffer solution (PBS) containing $3 \mathrm{mM} \mathrm{CTAB}$ (above CMC) at different $\mathrm{pH}$ value, until the final concentration of Cyt $c$ was $0.5 \mu \mathrm{M}$. The sizes of CTAB and CTAB-Cyt c nano micelle were determined to be 2.9 and $6.7 \mathrm{~nm}$, respectively, using a Dynamic light scattering (DLS) instrument (Zeta Plus, Brookhaven Instruments Corporation, America) (see Scheme 1).

The assay of the peroxidase activity of the AP was similar to previous methods [16-18]. A spectrophotometer (Model TU-1901, Beijing Purkinje General Instrument Company, China), $1 \mathrm{~cm}$ path length cells equipped with a thermostat holder and an external temperature controller (Shanghai

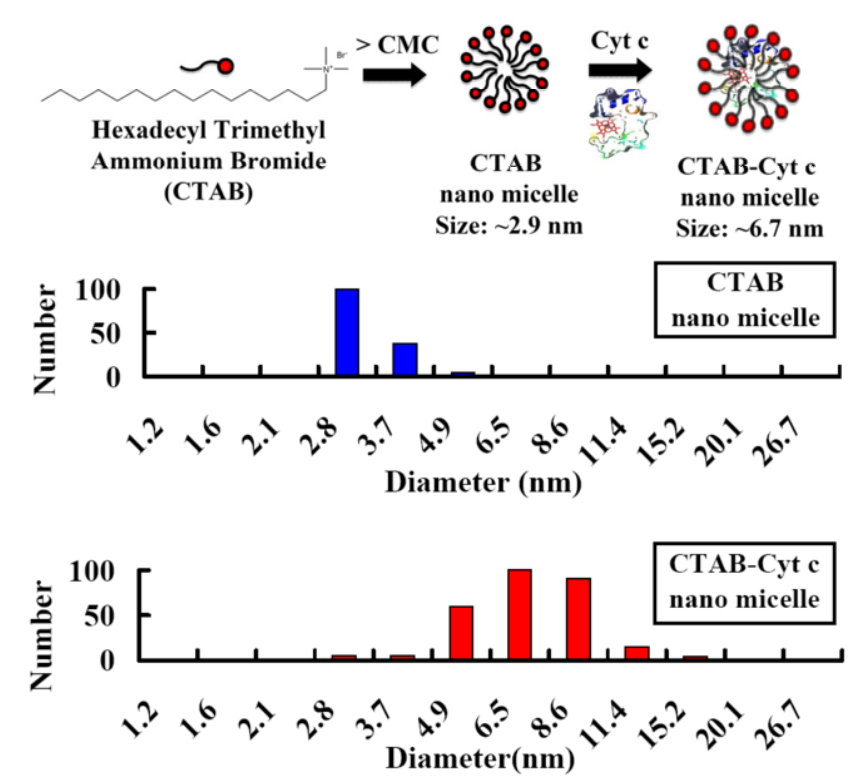

Scheme. 1. Preparation process of CTAB-Cyt $c$ nano micelle (AP). 
Hengping Instrument Company, China) were applied at $25^{\circ} \mathrm{C}$. The catalytic reaction was started by the addition of hydrogen peroxide after an amount of guaiacol was added to the cell. The beginning concentrations of guaiacol and $\mathrm{H}_{2} \mathrm{O}_{2}$ were $3.0 \mathrm{mM}$ and $1.0 \mathrm{mM}$, respectively. The initial guaiacol oxidation rate could be determined by the tetraguaiacol formation rate [16-18] at $470 \mathrm{~nm}$ in $100 \mathrm{mM}$ PBS at a certain pH value (Eq. (1)).

$$
4 \text { Guaiacol }+4 \mathrm{H}_{2} \mathrm{O}_{2} \longrightarrow \text { Teraguaiacol }+8 \mathrm{H}_{2} \mathrm{O}
$$

Extinction coefficient of tetraguaiacol was $26.6 \mathrm{mM}^{-1} \mathrm{~cm}^{-1}$ at $470 \mathrm{~nm}$. Ultraviolet-visible absorption and circular dichroism (CD) spectra of different components of AP were determined using aforementioned spectrophotometer and an Aviv 420SF (Lakewood, NJ) at $25^{\circ} \mathrm{C}$ [19]. The concentration of Cyt $c$ was $20 \mu \mathrm{M}$ for CD spectra determinations.

\section{Results and discussion}

\subsection{Influences of $p H$ values and CTAB concentrations on the guaiacol oxidation rate}

The influences of $\mathrm{pH}$ value on guaiacol oxidation rate are shown in Figure 1(A), the experiments were operated in PBS solution $(100 \mathrm{mM})$ with $3 \mathrm{mM} \mathrm{CTAB}, 10 \mu \mathrm{M}$ Cyt $c, 3.0 \mathrm{mM}$ guaiacol and 1.0 $\mathrm{mM}$ hydrogen peroxide at $25^{\circ} \mathrm{C}$. The reaction rate of the CTAB-Cyt $c$ nano micelle system increased rapidly with increase of $\mathrm{pH}$ value, until a maximum value (at $\mathrm{pH} 8.0$ ). It should be mentioned that the optimum $\mathrm{pH}$ of CTAB-Cyt $c$ nano micelle reduced significantly in comparison to that nano micelle of Cyt $c$-SDS [17]. However, the guaiacol oxidation rate for the natural Cyt $c$ reaction system in these studies was very low.

Figure 1(B) indicates the influences of $\mathrm{CTAB}$ micelle concentrations on the activity of the peroxidase-like enzyme in $100 \mathrm{mM}, \mathrm{pH} 8.0 \mathrm{PBS}$ containing $10 \mu \mathrm{M}$ Cyt $c, 3.0 \mathrm{mM}$ guaiacol and 1.0 $\mathrm{mM}$ hydrogen peroxide at $25^{\circ} \mathrm{C}$. The guaiacol oxidation rate of this system is dependent of CTAB concentrations above $\mathrm{CMC}$ and a platform was seen for $\mathrm{CTAB}$ at the concentration from 1.5 to 4.0 $\mathrm{mM}$. In fact, CMC of CTAB was determined in this report to be $0.90 \mathrm{mM}$ in $100 \mathrm{mM}$ PBS at pH 8.0, similar to $0.98 \mathrm{mM}$ in water [20].
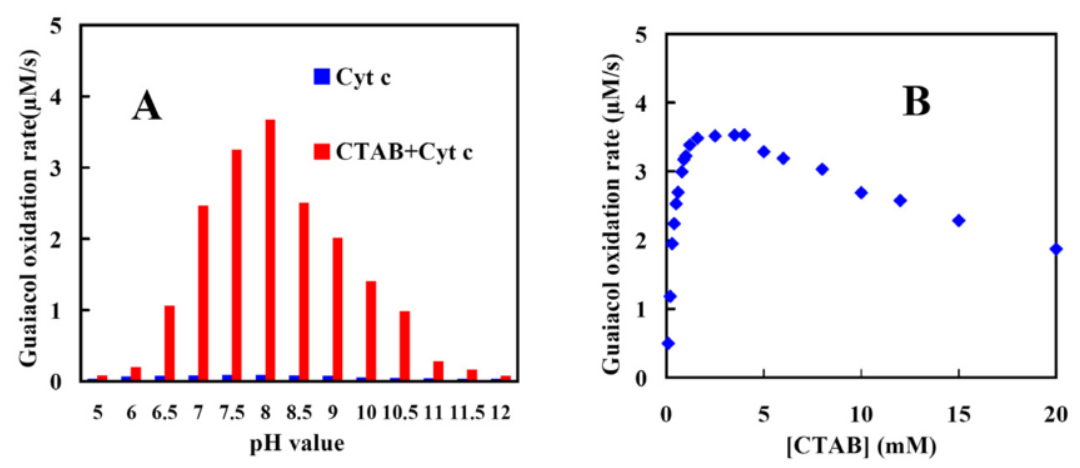

Fig. 1. Influences of $\mathrm{pH}$ values (A) $(3 \mathrm{mM} \mathrm{CTAB}, 10 \mu \mathrm{M}$ Cyt $c)$ and CTAB concentrations (B) $(10 \mu \mathrm{M}$ Cyt $c)$ on guaiacol oxidation rate in $\mathrm{pH} 8.0 \mathrm{PBS}(100 \mathrm{mM})$ with $3.0 \mathrm{mM}$ guaiacol and $1.0 \mathrm{mM}$ hydrogen peroxide. 
Table 1

Enzymatic kinetic parameters of different AP systems

\begin{tabular}{|c|c|c|c|c|c|}
\hline AP systems & $\mathrm{K}_{\mathrm{m}}(\mu \mathrm{M})$ & $\mathrm{k}_{\text {cat }}\left(\mathrm{s}^{-1}\right)$ & $\begin{array}{l}\text { Catalytic } \\
\text { Efficiency }\end{array}$ & $\begin{array}{l}\text { Relative Catalytic } \\
\text { Efficiency [17] }\end{array}$ & Refs. \\
\hline CTAB-Cyt $c$ nano micelle & $8.64 \pm 0.6$ & $0.311 \pm 0.013$ & $0.0360 \pm 0.002$ & $49.7 \pm 1.5 \%$ & $\begin{array}{l}\text { This } \\
\text { work }\end{array}$ \\
\hline Cyt $c$-SDS nano micelle & $21.6 \pm 1.2$ & $0.474 \pm 0.013$ & $0.0219 \pm 0.002$ & $30 \pm 1.5 \%$ & [16] \\
\hline Cyt $c$-NF nano cluster & $2.5 \pm 0.4$ & $0.069 \pm 0.001$ & $0.028 \pm 0.005$ & $39 \pm 5 \%$ & [19] \\
\hline Cyt $c$-His-SDS reverse micelle & 42 & 0.58 & 0.0173 & $24 \%$ & [21] \\
\hline $\begin{array}{l}\text { Gemini-SDS-Hemin- } \\
\text { Imidazole nano vesicular }\end{array}$ & 1.52 & 0.030 & 0.0198 & $27 \%$ & [22] \\
\hline $\begin{array}{l}\text { His-hematin-SDS nano } \\
\text { micelle }\end{array}$ & 3.31 & 0.0433 & 0.0131 & $18 \%$ & [18] \\
\hline Native HRP & 5800 & 420 & 0.0724 & $100 \%$ & {$[18]$} \\
\hline
\end{tabular}

\subsection{Enzymatic kinetic parameters of AP}

The enzymatic kinetic parameters of $\mathrm{k}_{\mathrm{cat}}, \mathrm{K}_{\mathrm{m}}$ and $\mathrm{k}_{\mathrm{cat}} / \mathrm{K}_{\mathrm{m}}$ of different AP reaction systems are shown in Table 1. Here, $\mathrm{k}_{\mathrm{cat}}$ means the maximum moles of guaiacol turned into tetraguaiacol during unit time for one mole catalyst, and $\mathrm{K}_{\mathrm{m}}$ indicates a function of guaiacol concentration for different AP models. The mentioned kinetic parameters could be determined from the linearized Lineweaver-Burk plot (Eq. (2)).

$$
\frac{1}{V_{0}}=\frac{K_{m}}{V_{\max }[S]}+\frac{1}{V_{\max }}
$$

Where, $\mathrm{V}_{0}$ is the initial guaiacol oxidation reaction rate. Then, $\mathrm{k}_{\mathrm{cat}}$ and $\mathrm{K}_{\mathrm{m}}$ of the AP were determined to be $0.311 \pm 0.013 \mathrm{~s}^{-1}$ and $8.64 \pm 0.60 \mu \mathrm{M}$, respectively. The catalytic efficiency $\left(\mathrm{k}_{\text {cat }} / \mathrm{K}_{\mathrm{m}}\right)$ of the AP was $0.0360 \pm 0.0020 \mu \mathrm{M}^{-1} \mathrm{~s}^{-1}$. This value $(49.7 \pm 1.5 \%$ efficient of native HRP) means that the prepared AP could be used instead of HRP.

\subsection{Ultraviolet-visible and CD spectra investigations on AP and natural Cyt $c$}

Ultraviolet-visible spectra of AP $(10 \mu \mathrm{M}$ Cyt $c+3 \mathrm{mM}$ CTAB $)$ and native Cyt $c(10 \mu \mathrm{M})$ in 100 mM PBS pH 8.0 are shown in Figure 2(A). It could be seen that the UV-vis spectra of $3 \mathrm{mM}$ CTAB were very weak in the range from 300 to $500 \mathrm{~nm}$. Moreover, the absorption peak wavelength for the heme group in the AP and natural Cyt $c$ were 408 and $409 \mathrm{~nm}$, respectively, at $\mathrm{pH} 8.0$. The maximum wavelength $\left(\lambda_{\max }\right)$ and $\mathrm{Abs}\left(\mathrm{Abs}_{\max }\right)$ of the heme absorption peak depending on $\mathrm{pH}$ values were shown in Figures 2(a) and 2(b) (inset), respectively. It was worth noticing that the $\mathrm{Abs}_{\max }$ for AP and Cyt $c$ was decreased and increased, respectively, with increased $\mathrm{pH}$ value, and met at about $\mathrm{pH} 8.2$, which maybe also the optimum $\mathrm{pH}$ value for the AP. Moreover, at $\mathrm{pH}$ 8.0, there is a Blue Shift (about $1 \mathrm{~nm}$ ) for $\lambda_{\max }$ of AP respect to Cyt $c$. It appears that CTAB micelle offers Cyt $c$ a hydrophobic situation, meanwhile, it also cause the exposure of the heme group [23].

Far-Ultraviolet, near and Soret CD spectra are very important in investigation on the secondary and 

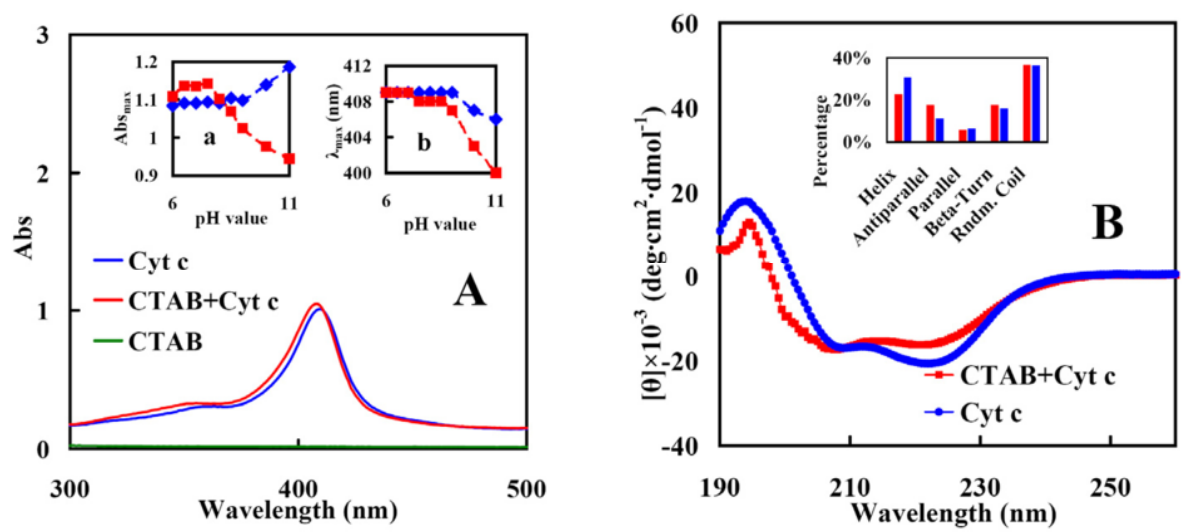

Fig. 2. (A) Ultraviolet-visible spectra of $\mathrm{AP}(10 \mu \mathrm{M}$ Cyt $c+3 \mathrm{mM} \mathrm{CTAB})$ and native Cyt $c(10 \mu \mathrm{M})$ in $100 \mathrm{mM}, \mathrm{pH} 8.0 \mathrm{PBS}$. Insets show $\mathrm{pH}$ influences of (a) $\mathrm{Abs}_{\max }$ and (b) $\lambda_{\max }$ of Soret Peak. (B) Far-Ultraviolet-CD spectra of AP (20 $\mu \mathrm{M}$ Cyt $c+3$ $\mathrm{mM} \mathrm{CTAB})$ and Cyt $c(20 \mu \mathrm{M})$. Inset: contents of different secondary structures of AP $(20 \mu \mathrm{M}$ Cyt $c+3 \mathrm{mM} \mathrm{CTAB})$ and Cyt $c(20 \mu \mathrm{M})$. The $\mathrm{CD}$ spectra were determined in $10 \mathrm{mM}$, pH $8.0 \mathrm{PBS}$ at $25^{\circ} \mathrm{C}$.

tertiary structure of a protein $[21,24]$. The CD spectra of AP and Cyt $c$ in $\mathrm{pH} 8.0$ PBS $(10 \mathrm{mM})$ is shown in Figure 2(B). Double minima could be seen at $222 \mathrm{~nm}$ and $208 \mathrm{~nm}$ for native Cyt $c$. For AP, the minima would become stronger at $208 \mathrm{~nm}$ and weaker at $222 \mathrm{~nm}$, respectively. Moreover, at $\mathrm{pH}$ 8.0, prepared AP has a Blue Shift (about $1 \mathrm{~nm}$ ) and stronger absorption peak in comparison to that of Cyt $c$ in Soret and near CD spectra of AP (data not shown). The content of different secondary structure of AP and Cyt $c$ at $\mathrm{pH} 8.0$ was shown in Figure 2(B) inset, collected with a spectrum deconvolution software. It could be seen that the Cyt $c$ and AP had different secondary structures, the content of the alpha helix and parallel components reduced from $30.5 \%$ and $6.3 \%$ of Cyt $c$ to $22.5 \%$ and $5.8 \%$ of AP, respectively. Meanwhile, the contents of beta-turn and anti-parallel structures increased from $15.8 \%$ and $11.1 \%$ of Cyt $c$ to $17.6 \%$ and $17.6 \%$ of AP, respectively. There is little difference between Cyt $c$ and AP for Rndm coil structure. This might suggest that the alpha-helix structure in the AP might become into a folded structure [21, 25-26].

\section{Conclusions}

A CTAB-Cyt $c$ nano-micelle structure with high peroxidase catalytic efficiency was designed when the Cyt $c$ molecule was embraced by self-assembly in CTAB nano-micelle. The CTAB micelle could help Cyt $c$ to generate hydrophobic patches near the heme group of Cyt $c$ and lead the heme structure to more exposure, which make the Cyt $c$ form an ordinary protein to a highly catalytic efficient AP.

\section{Acknowledgments}

The support of Development Projects of Henan Province Science and Technology (142300410124), Henan University Science Foundation (Y1425013), the Research Council of University of Tehran and Iran National Science Foundation (INSF) are gratefully acknowledged. 


\section{References}

[1] Y. Murakami, J. Kikuchi, Y. Hisaeda and O. Hayashida, Artificial enzymes, Chemical Reviews 96 (1996), 721-758.

[2] R. Radi, J.F. Turrens and B.A. Freeman, Cytochrome c-catalyzed membrane lipid peroxidation by hydrogen peroxide, Archives of Biochemistry and Biophysics 288 (1991), 118-125.

[3] G.D. DePillis, S. Ozaki, J.M. Kuo, D.A. Maltby and P.R. Ortiz de Montellano, Autocatalytic processing of heme by lactoperoxidase produces the native protein-bound prosthetic group, The Journal of Biological Chemistry 272 (1997), $8857-8860$.

[4] R. Vazquez-Duhalt, K.M. Semple, D.W.S. Westlake and P.M. Fedorak, Effect of water-miscible organic solvents on the catalytic activity of cytochrome c, Enzyme and Microbial Technology 15 (1993), 936-943.

[5] A.A. Moosavi-Movahedi, J. Chamani, Y. Goto and G. Hakimelahi, Formation of the molten globule-like state of cytochrome c induced by n-alkyl sulfates at low concentrations, The Journal of Biochemistry 133 (2003), 93-102.

[6] A.A. Moosavi-Movahedi, M.R. Dayer, P. Norouzi, M. Shamsipur, A. Yeganeh-Faal, M.J. Chaichi and H.O. Ghourchian, Aquamethemoglobin reduction by sodium n-dodecyl sulfate via coordinated water oxidation, Colloids and Surfaces B: Biointerfaces 30 (2003), 139-146.

[7] A.A. Moosavi-Movahedi, Thermodynamics of proteins denaturation by sodium dodecyl sulfate, Journal of the Iranian Chemical Society 2 (2005), 189-196.

[8] A. Naeem and R.H. Khan, Characterization of molten globule state of cytochrome c at alkaline, native and acidic $\mathrm{pH}$ induced by butanol and SDS, The International Journal of Biochemistry \& Cell Biology 36 (2004), 2281-2292.

[9] M.N. Jones, A. Finn, A. Mosavi-Movahedi and B. Waller, The activation of aspergillus niger catalase by sodium ndodecyl-sulphate, Biochimica et Biophysica Acta (BBA)-Protein Structure and Molecular Enzymology 913 (1987) 395-398.

[10] W. Parker and P.S. Song, Protein structures in SDS micelle-protein complexes, Biophysical Journal 61 (1992) 14351439.

[11] R. Montserret, M.J. McLeish, A. Böckmann, C. Geourjon and F. Penin, Involvement of electrostatic interactions in the mechanism of peptide folding induced by sodium dodecyl sulfate binding, Biochemistry 39 (2000), 8362-8373.

[12] A.A. Moosavi-Movahedi, J. Chamani, M. Gharanfoli and G.H. Hakimelahi, Differential scanning calorimetric study of the molten globule state of cytochrome c induced by sodium n-dodecyl sulfate, Thermochimica Acta 409 (2004), 137144.

[13] P. Brochette, C. Petit and M.P. Pileni, Cytochrome $\mathrm{c}$ in sodium bis (2-ethylhexyl) sulfosuccinate reverse micelles: Structure and reactivity, The Journal of Physical Chemistry 92 (1988), 3505-3511.

[14] R. Radi, J.F. Turrens and B.A. Freeman, Cytochrome c-catalyzed membrane lipid peroxidation by hydrogen peroxide, Archives of Biochemistry and Biophysics 288 (1991), 118-125.

[15] G.D. DePillis, S. Ozaki, J.M. Kuo, D.A. Maltby and P.R. Ortiz de Montellano, Autocatalytic processing of heme by lactoperoxidase produces the native protein-bound prosthetic group, The Journal of Biological Chemistry 272 (1997), $8857-8860$.

[16] J. Hong, K. Huang, W. Wang, W.Y. Yang, Y.X. Zhao, B.L. Xiao, Z. Moosavi-Movahedi, H. Ghourchian, N. Sheibani and A.A. Moosavi-Movahedi, Direct electrochemistry of artificial peroxidase based on self-assembled cytochrome cSDS-nano-micelle, Analytical Letters 45 (2012), 2221-2235.

[17] J. Hong, K. Huang, W. Wang, W.Y. Yang, Y.X. Zhao, B.L. Xiao, Z. Moosavi-Movahedi, H. Ghourchian, M. Bohlooli, N. Sheibani and A.A. Moosavi-Movahedi, Journal of the Iranian Chemical Society 9 (2012), 775-782.

[18] A.A. Moosavi-Movahedi, F. Semsarha, H. Heli, K. Nazari, H. Ghourchian, J. Hong, G.H. Hakimelahi, A.A. Saboury and Y. Sefidbakht, Micellar histidinate hematin complex as an artificial peroxidase enzyme model: Voltammetric and spectroscopic investigations, Colloids and Surfaces A: Physicochemical and Engineering Aspects 320 (2008), $213-221$.

[19] J. Hong, W. Wang, K. Huang, W.Y. Yang, Y.X. Zhao, B.L. Xiao, Y.F. Gao, Z. Moosavi-Movahedi, S. Ahmadian, M. Bohlooli, A.A. Saboury, H. Gjourchian, N. Sheibani and A.A. Moosavi-Movahedi, A self-assembled nano-cluster complex based on cytochrome $\mathrm{c}$ and nafion: An efficient nanostructured peroxidase, Biochemical Engineering Journal $\mathbf{6 5}$ (2012), 16-22.

[20] M.J. Rosen and J.T. Kunjappu, Surfactants and Interfacial Phenomena, 3rd ed., John Wiley \& Sons, New York, 2004, p. 128.

[21] F. Farivar, A.A. Moosavi-Movahedi, Y. Sefidbakht, K. Nazari, J. Hong and N. Sheibani, Cytochrome c in sodium dodecyl sulfate reverse micelle nanocage: From a classic electron carrier protein to an artificial peroxidase enzyme, Biochemical Engineering Journal 49 (2010), 89-94.

[22] H. Gharibi, Z. Moosavi-Movahedi, S. Javadian, K. Nazari and A.A. Moosavi-Movahedi, Vesicular mixed gemini-SDS-hemin-imidazole complex as a peroxidase-like nano artificial enzyme, Journal of Physical Chemistry 115 (2011), 4671-4679. 
[23] Y.P. Myer, A.F. Saturno, B.C. Verma and A. Pande, Horse heart cytochrome c: The oxidation-reduction potential and protein structures, Journal of Biological Chemistry 254 (1979), 11202-11207.

[24] N. Mogharrab, H. Ghourchian and M. Amininasab, Structural stabilization and functional improvement of horseradish peroxidase upon modification of accessible lysines: Experiments and simulation, Biophysical Journal 92 (2007), 11921203.

[25] N. Mogharrab and H. Ghourchian, Anthraquinone 2-carboxylic acid as an electron shuttling mediator and attached electron relay for horseradish peroxidase, Electrochemistry Communications 7 (2005), 466-471.

[26] G. Blauer, N. Sreerama and R.W. Woody, Optical activity of hemoproteins in the Soret region: Circular dichroism of the heme undecapeptide of cytochrome $\mathrm{c}$ in aqueous solution, Biochemistry 32 (1993), 6674-6679. 